\title{
Modelling Crop Pattern Changes and Water Resources Exploitation: A Case Study
}

\author{
Donato Zingaro $^{1}$ (D), Ivan Portoghese ${ }^{1, *}$ and Giacomo Giannoccaro ${ }^{2}$ \\ 1 National Research Council Water Research Institute, UOS Bari, Via F. De Blasio, 5, 70132 Bari, Italy; \\ donato.zingaro@ba.irsa.cnr.it \\ 2 Department DiSAAT, University of Bari, Via Orabona 4, 70126 Bari, Italy; giacomo.giannoccaro@uniba.it \\ * Correspondence: ivan.portoghese@cnr.it; Tel.: +39-080-5820540
}

Received: 29 June 2017; Accepted: 6 September 2017; Published: 8 September 2017

\begin{abstract}
Agriculture and farming worldwide are responsible for numerous environmental threats, including degradation of land and water resource depletion. Underlining the dynamic interaction between bio-physical and socio-economic drivers is the key towards a more sustainable land and water management. With regard to a highly-developed agricultural area in Southern Italy, multi-regression models were developed to provide an ex-post interpretation of the observed inter-annual variability of cropped land. The main drivers related to Common Agricultural Policy support, product market prices, crop yield, and irrigation water availability were investigated. The adopted models revealed the different weights of each driver. The findings reported the role that direct payments played in supporting the extension of irrigated crops, such as processing tomato. Likewise, the models pointed out the decoupled payment scheme as the most important driver of change in the crop pattern over the last years.
\end{abstract}

Keywords: land and water management; land use change modelling; water and irrigation policy; modelling of policy impact

\section{Introduction}

Starting from the 1960s, there has been growth in both food production and the global population [1]. As the global population will continue to grow in the coming decades, at the same time, food demand will increase while food producers are expected to experience greater competition for land, water, and energy [1].

As such, agriculture and farming are, in general, responsible for increasing environmental threats, including degradation of land and freshwater [2]. The technological innovations allowed a rapid increase in agricultural productivity [3] during the last fifty years. In fact, the world's agricultural production grew about three times over this period, while the cultivated land grew $12 \%$. More than $40 \%$ of the growth in food production comes from irrigated land, which has doubled its area and can be interpreted as a global signal of the increasing degree of pressure on water resources [3].

Major water resources exploited for irrigation are surface and groundwater bodies. For many production areas, groundwater remains the unique source of freshwater when surface water sources are not available [4]. As a whole, irrigation is currently responsible for groundwater withdrawals of about $2800 \mathrm{~km}^{3}$ per year [5]. In fact, irrigation represents the most impacting water use on groundwater resources [6], as it accounts for $70 \%$ of global withdrawals and $90 \%$ of consumptive water uses [7]. The irrigation water demand depends primarily on the extension of irrigated land, which ultimately depends on farmers' decisions. As found in some studies [8] farmers' behavior with respect to cropping pattern is driven by economic factors, such as market prices, agricultural subsidies, land, and capital availability. 
Focusing on the European Union, the Common Agricultural Policies (CAP) were traditionally introduced as a balancing tool to help national production to compete in both domestic and international markets [9]. Moreover, agricultural policies enable farming profitability [10], which produce direct and indirect values in terms of landscape conservation and cultural heritage. On the other hand, the role of agricultural policies is secondarily connected to water resource sustainability and protection [11]. Specific policies for water resource protection often failed due to their direct and indirect contrast with farmers' support policies $[12,13]$. Although other policies strictly focused on the diffusion of water-saving technologies, it has not proved to be efficient in controlling irrigation water demand by adjusting the cropping towards more sustainable water resource patterns [14].

Broadly speaking, a cropping plan, or pattern, refers to the acreages occupied by all the different crops every year [15] and can be reported at the farm level where most of decisions are made [16], or at a higher level in order to address collective issues [17]. A number of studies have tried to explain the cropping pattern evolutions as a function of market and policy drivers. Econometric models for crop production can also be developed to understand past dynamics of crop productions, evaluate policy effects, and design new policies to enhance economic productivity and environmental conservation [18]. Two types of models are available to describe cropping plans: cropping plan selection models which are used to support stakeholder decisions (farmers, policy-makers, and other stakeholder), and cropping plan decision models, which explicitly refer to decision-making behavior (e.g., in the field of agricultural economics) and are used to imitate stakeholder decisions to assess large-scale changes [18]. On a large scale, the collective decisions of farmers are generated by all individual decisions mediating the impact of policy and market changes on land-use [19] and have been treated in agricultural economics for policy analysis and forecasting [20]. The model developed in this study belongs to the category of cropping plan decision models applied at the large scale. While the agricultural economy literature is mostly focused on ex-ante policy assessment, the developed model allows the ex-post evaluation of policy measures together with the other economic and physical (i.e., water availability) drivers influencing large scale cropping patterns during a significant time horizon.

The present study concerns the Province of Foggia (Puglia region, Southern Italy), which represents a highly-developed agricultural area and is the largest irrigated area of Puglia (Southern Italy). The irrigation service is provided and managed by the Reclamation and Irrigation Board of Capitanata (CBC), which covers $84 \%$ of the utilized agricultural area (UAA) of the province. The CBC adopts volumetric block tariffs, whereby farmers pay according to their actual consumption. However, the surface water resources of the $\mathrm{CBC}$ is integrated with on-farm groundwater resources from private pumping wells. In fact, the water derived from surface water (SW) bodies is not enough to fulfil irrigation water requirements, so groundwater $(\mathrm{GW})$ resources are widely exploited to fulfil crop water demands in the study area. As a result, the GW level has been dramatically decreasing during the last decades [21] and is likely to be further depleted due to climate change [22]. It is, therefore, crucial to investigate the possible evolution of irrigation requirements which, in turn, depend on cropping pattern changes, to reach a sustainable management of water resources.

Multi-regression models were developed to interpret the inter-annual variability of cropland devoted to processing tomato (an intensive crop with a high irrigation water requirement) and durum wheat (an extensive, rain-fed crop) under the variability of the main drivers related to CAP support, market prices, crop yield, and water availability. Our working hypothesis is that water availability, together with crop economic profitability, may have shaped the evolution of cropping patterns and water resource exploitation. The purpose of the present study is to shed light on drivers of cropping patterns and their impacts on irrigation water requirement.

The article is organized as follows: After this introduction, Section 2 presents the study case; Section 3 reviews some major variables and hypotheses of modelling and, in addition, presents the adopted modelling approach; The parameterization process for two multi-regression models, and the results and discussion are presented, respectively, in Sections 4 and 5; The last section draws concluding remarks. 


\section{Study Area}

\subsection{Overview}

The case study of the present work corresponds to a fertile plain named Tavoliere covering about $5000 \mathrm{~km}^{2}$, where cereal production has existed since the Roman age. The climate of the area is classified as Cfa (warm temperate, fully humid, hot summer) according to the updated Köppen-Geiger climate classification [23], while the hydro-geological setting is characterized by a significant river network with a marked seasonal streamflow regime.

At the provincial scale, the UAA covers 495,100 ha, corresponding to $92 \%$ of the total agricultural area [24]. This production area is relevant for the intensive farming, particularly for the production of processing tomato, which accounts for $33 \%$ of the national production. In more detail, the crop pattern is characterized mostly by rain-fed winter cereals (with durum wheat covering $47 \%$ of the UAA), irrigated horticultural summer crops (with processing tomato covering $4 \%$ ), forage and pasture systems (15\%), olive trees and vineyards (15\%), and the remaining agricultural area (19\%) being covered by less representative permanent and seasonal crops. The irrigation network is available approximately on 150,000 ha, but only 126,000 ha are effectively supplied. Two irrigation systems are established within the area: the Fortore district, in the northern part, serving 110,000 ha, and the Sinistra Ofanto district, in the south, serving approximately 40,000 ha. Both are on-demand pressurized districts, with volumetric water pricing, and delivering points equipped with water-meters, of which $10 \%$ use prepaid card devices to monitor water demand [25]. Water resource conveyance (i.e., dams and diversions) and delivery systems of both districts are managed by the CBC, which is a governing and technical body ruled by farmers' representatives.

The significant alluvial aquifers located between the hilly area of the sub-Apennines (southwest) and Gargano area (northeast) represent important water resources for the whole area, even if the pumping rate per well is quite limited. Groundwater exploitation is operated through private wells used to increase the farm irrigation capacity, particularly when SW supply is insufficient. As a matter of fact, during the last 30 years the number of licenses reached about 45,000 over the CBC area [26]. Consequently, the Tavoliere aquifer complex was recognized as the most overexploited of the region and the release of new abstraction permissions was suspended [27]. Moreover, the lack of accurate GW monitoring on such a wide area has favored the spreading of illegal wells [26].

The annual irrigation requirement for the Province of Foggia is estimated around $300 \mathrm{Mm}^{3}$ (mean annual value in the period 2000-2014) and is covered with a share of groundwater resources around $66 \%$. The case study can, therefore, be considered as an example of joint use of limited surface water (SW) under a centralized authority for delivery and control (i.e., CBC) and groundwater (GW), which is exploited by a large number of small users [28].

Over the last 15 years, the study area has experienced a relevant evolution in the traditional cropping patterns that reflected on surface water and groundwater resource management.

\subsection{Variations of Crop Areas and Irrigation Requirement}

In this research two crops were considered, namely winter durum wheat and processing tomato. These are representative of two contrasting types of crop (i.e., extensive vs. intensive, rain-fed vs. irrigated, winter vs. summer crops) with distinct pressures on land and water resources.

In particular, for the period under investigation ranging from 2000 to 2014, two datasets were considered, one from the National Statistical Service [29] for the period 2000-2011 and one from the National Service for Agricultural Economy [30] for the period 2012-2014. During the whole period, large areal variations, mostly due to the CAP reform implementation between 2000 and 2009, were observed for both durum wheat (between 282,000 ha in 2002 and 165,000 ha in 2011) and for processing tomato (between 30,000 ha in 2000 and 16,670 ha in 2013). Moreover, the areal variation of the other crop types was also considered to characterize the evolution of irrigation requirements. In Figure 1, provincial area variations of investigated crops are shown. 


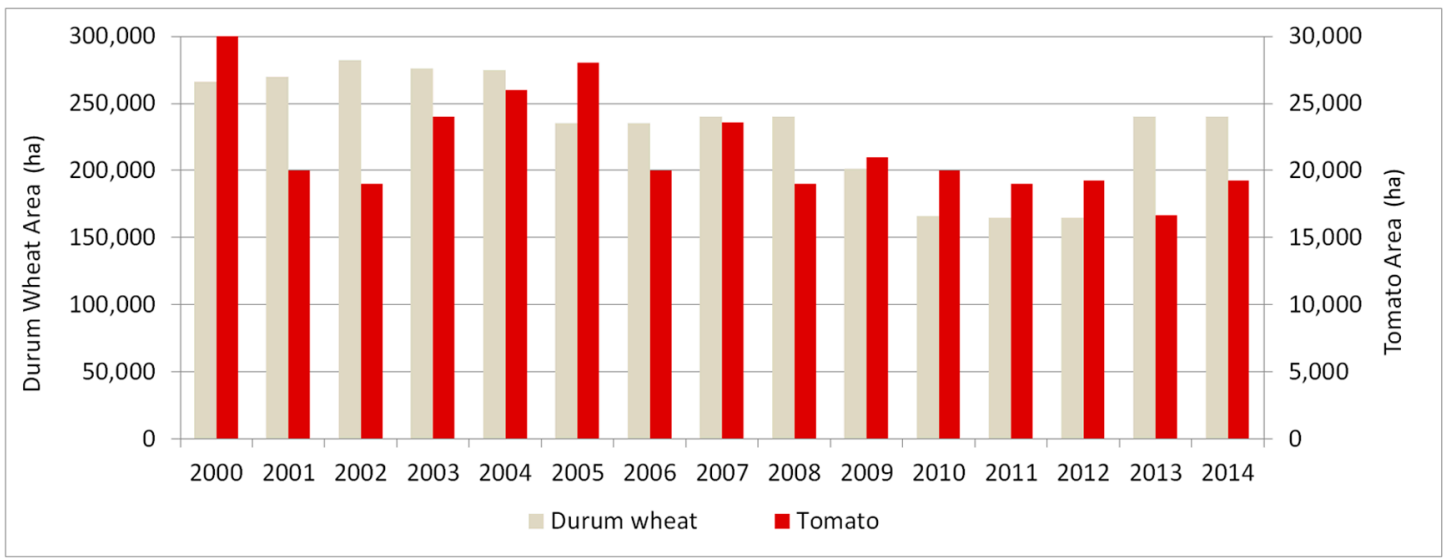

Figure 1. Cropping area variations.

The total irrigation requirement of the study area is variable according to the seasonal climate variability and to the inter- and intra-annual evolution of cropping patterns. Starting from the dataset of agricultural land use, the monthly variability of irrigation requirement was estimated throughout the period of interest, according to Zingaro et al. [31].

At the whole district scale (CBC), the resulting water needs are reported in Figure 2 and compared with the annual supply volumes from SW resources (Fortore and Sinistra Ofanto districts) based on the observations provided by the Regional Water Authority. Figure 2 shows a weak correlation between SW supply and water needs, also highlighting a relevant share of the irrigation requirement that has to be necessarily fulfilled through GW pumping. Overexploitation of GW is more likely to happen during drought periods, as the difference between irrigation requirement and SW supply suggests in Figure 2.

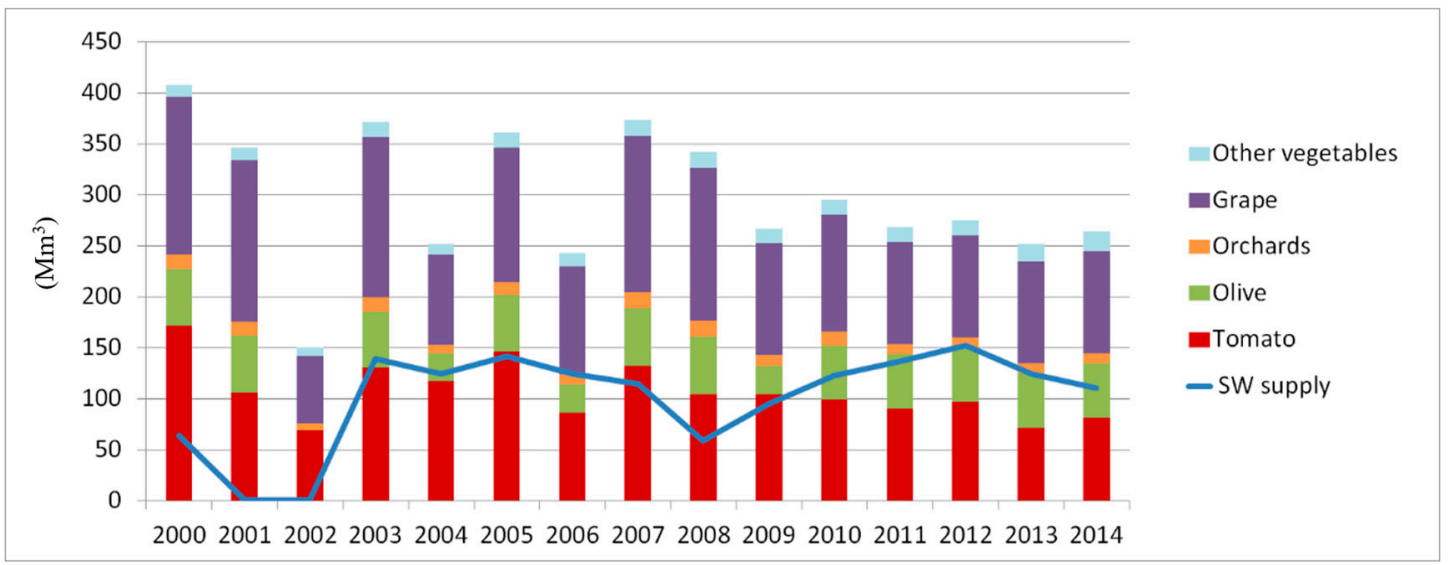

Figure 2. Irrigation water requirement (piled bars) and surface water (SW) supply (blue line).

The nexus between irrigation demand and GW exploitation in the area was recently investigated, especially under surface water scarcity conditions [28]. Therefore, GW resources are considered as supplementary irrigation sources during regular hydrological seasons, becoming an alternative irrigation source under drought conditions. As such, GW resources are perceived by farmers as a private good always available for their needs. On the other hand, the lower GW water quality and limited pumping rate correspond to higher energy and labor costs compared to the SW resource supplied by the pressurized network.

In conclusion, due to the stable, but low-quality of GW supply, we assumed that the influence of GW availability is negligible on the crop pattern change. While the higher standard of the SW supply 
service is considered as highly influential on the cropping pattern, as confirmed by the reduction of processing tomato area in years with low availability of SW resource (e.g., 2001 and 2002) aiming to reduce yield losses. Consequently, a SW index (see Section 3.2.1) is considered as a suitable indicator to represent the water availability influence on crop pattern change.

\section{Materials and Methods}

\subsection{Framework}

Understanding drivers of land use changes may assist in developing a sustainable management of land and water resources in the future. It is assumed that the observed cropland extension is directly linked to farmers' decisions which depend on other external drivers. With this study, the interactions between historical areal variations and influencing drivers are analysed.

The adopted methodology involves the following steps: Initially, a comparison between temporal series of influencing drivers and observed variations of crop area was performed with the purpose of studying possible correlations. Connections between drivers and areal variations, in terms of polarities and possible delayed influences, was drafted considering the expert knowledge, besides the abovementioned comparison, and following the approach proposed in Giordano et al. [32] through semi-structured interviews with local stakeholders. The result of this step was explicated by means of conceptual maps. Then, a multi-regression modelling approach was adopted [33] to define the structure of the models' equations. Conceptual maps and model equations were implemented using the STELLA ${ }^{\circledR}$ tool (isee systems, Lebanon, NH, USA), which allowed taking into account the network of interactions, including delay mechanisms influencing the system dynamic evolution [34], throughout the period of interest. The equations' parameters were estimated by means of the least square method using the PEST ${ }^{\circledR}$ software package (the PEST project, Reading, England, UK) for parameter estimation [35] on the basis of the historic values of crop areas. Finally, a sensitivity analysis (SA) was performed to investigate how the variation in the model output can be attributed to variations of its input drivers [36].

Considering the very simple structure of adopted multi-regression models (MRM) together with the peculiar variability of MRM input variables, a SA approach was undertaken with the specific purposes of ranking, screening and mapping the distinctive roles of the input drivers according to Saltelli et al. [37]. The SA was performed splitting the period of interest and the corresponding model structure into two parts, one with the coupled agricultural support scheme and the other with the decoupled support scheme, trying to highlight the relative contribution to the crop area variability under regular, intermediate, and drought conditions (see Section 4.4).

\subsection{Description of Main Drivers}

The farmers' choice regarding the evolution of cultivated area is differently affected by many drivers both of physical and non-physical nature [2]. These drivers can be of an economic nature, such as market prices and policy subsidies, or of a climatic and phytosanitary nature, such as crop yield, or related to the availability of water for irrigation [38]. All of them contribute in shaping the evolution of cropping patterns which can be assumed as the product of farmers' decisions mostly based on income maximization purposes. Focusing on investigated crops, the changes in processing tomato and durum wheat areas were analyzed and compared against the observed changes of subsidies, crop yield, market price, and irrigation water availability. Therefore, the analysis is based on the assumption that these four drivers are the most influential in the study area, since these are recognized as major revenue drivers on agricultural productivity [39] and, therefore, these drivers act on farmer's decisions towards annual maximization of economic returns even when such influencing drivers undergo some structural of unpredictable changes. 


\subsubsection{Surface Water (SW) Stress Index}

Considering the present case study, the area devoted to processing tomato is mainly located within the Fortore district, as reported in [40] and summarized in [24]. Therefore, the availability of SW was defined on the basis of information about the Fortore district, which is supplied by the Occhito dam.

Although the CBC applies a volumetric water pricing with a three-tier scheme, the water tariffs are actually established from year to year by the $C B C$ irrigation managing authority. Through semi-structured interviews with $\mathrm{CBC}$ managers, it was derived that, from a merely technical standpoint, the annual decision on the irrigation water tariffs reflects the water scarcity condition corresponding to the volume stored in the reservoir (Occhito) soon before the start of the irrigation season (i.e., March) [32].

Over the study period, different tariff plans were implemented according to the available water in the reservoir. The correlation between the accessibility of SW supply and the first block volume (with minimum tariff) in each year was, therefore, investigated. In particular, under water scarcity conditions, the $\mathrm{CBC}$ managers tend to lower the first block volume from $2050 \mathrm{~m}^{3} /$ ha of regular seasons, down to $600 \mathrm{~m}^{3} /$ ha for severe water scarcity seasons. This relationship between SW availability and corresponding first block volumes was condensed into a SW stress index (SI) ranging from 0 in regular SW supply years to 1 in years when irrigation service from SW system is not feasible at all (Figure 3).

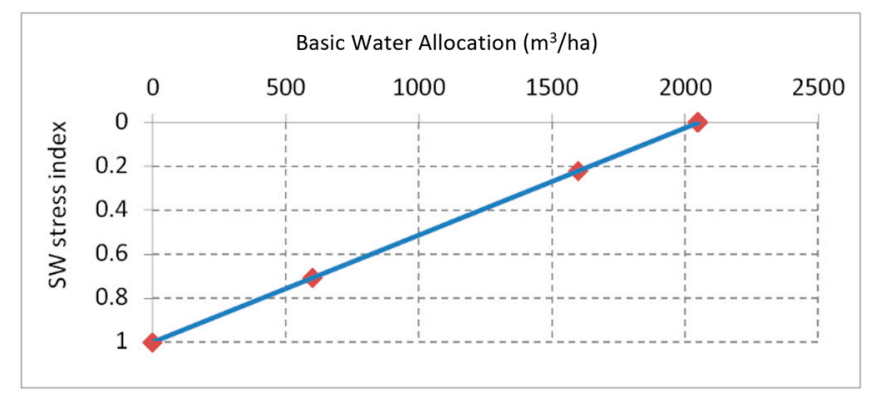

Figure 3. Stress index (SI) related with BWA (blue line) and observed value (red circles).

\subsubsection{Market Price and Crop Yield}

Datasets on market prices for the interested period were derived from different sources, such as the local market trade chamber (Camera di Commercio di Foggia, CCF), the institute of agricultural economy (ISMEA), and from technical journal papers reporting market prices collected from farmers' organizations for quite a long period [41].

According to the reference dataset, the market price for processing tomato varied between $60 € / \mathrm{t}$ (2005) and $120 € / t$ (2008). Mainly, the observed fluctuations were related to the harvested production, as a result of the year-to-year crop yield and cultivated area and, therefore, according the supply and demand market law.

Regarding the variability of wheat market price, the dataset available from the CCF clearly reflected the global price variation of commodities markets, though with differences due to climate-yield singularities. Market price has varied between $140 € / \mathrm{t}$ (in 2005) and $355 € / \mathrm{t}$ (in 2008) for durum wheat.

To take into account also the variability on crop yield, the ISTAT dataset [29] concerning crop areas and production volumes was elaborated to obtain the annual production per unit area (in $t / h a$ ). The datasets concerning production volume and market prices were combined by obtaining the annual series of Gross Product Volume (GPV), which is measured in $€$. 


\subsubsection{Change in the Structure and Intensity of Subsidies}

During the analysed period, subsidies connected to the Common Agricultural Policy (CAP) were deeply reframed in structure and intensity. For the time horizon of the present study, the main CAP reform begun in 1992 with the MacSharry Reform, which reduced the level of market price support (MPS) and introduced a concept of direct payment in order to reduce the level of market distortion, for the period 1994-2000. In 2000, there was the Agenda 2000 Reform, which introduced a further reduction of market price support also focusing on environmental targets. In 2003, the Fischler Reform was approved which introduced the decoupling of almost all direct payments linked to production, in order to disrupt the loop between incentives and the increase of production, and to push farmers to respond more tightly to the market signals. From 2004 to 2008, the coupled direct payments and decoupled payments varied, respectively, from $77 \%$ to $15 \%$ and $3 \%$ to $68 \%$ of total CAP payments [42]. In 2008 the CAP introduced a Health Check Reform that completed the decoupling process. With this reform the complete decoupling of payments from production was intended to lead farmers' crop decisions to be independent from subsidies. Consequently, farmers who received subsidies in the past for a specific crop were not forced to carry on the same crop. Moreover, the Health Check Reform has given particular importance to the green economy, environmental sustainability, and to increase the competitiveness of the EU agricultural sector [43].

Moreover, in the case of processing tomato, there were various changes in the farmers' support scheme during the study period [44]. For the period 2000-2007, the tomato was supported by means of a market price support (named MPS in Figure 4), so the subsidies were related to production volumes according to Reg. (CE) 2201/96 as much as $34.50 € / t$ [45]. For the period 2008-2010, there was a period of transition (named $\mathrm{T}$ in Figure 4) with a progressive decoupling process of support, in which the specific crop payments moved from the product to producers, thus reducing the profitability of the crop production. In Italy, the Ministry of Agriculture adopted a transitional period preserving part of the coupled payment (50\%) besides the decoupled payment [44], in agreement with Reg. (CE) 1182/2007 and Dm. 1129 of 31/1/08. The amount of coupled payment was about $1250 € /$ ha [45]. However, the decoupled payment, provided only to historical producers, was related to fixed production at the farm-scale and based on the average crop area in the period 2004-2006. For the period 2011-2014 (named Decoupled in Figure 4), the support after the Health Check Reform reached the full decoupling of the total payment according to Reg. (CE) 73/2009.

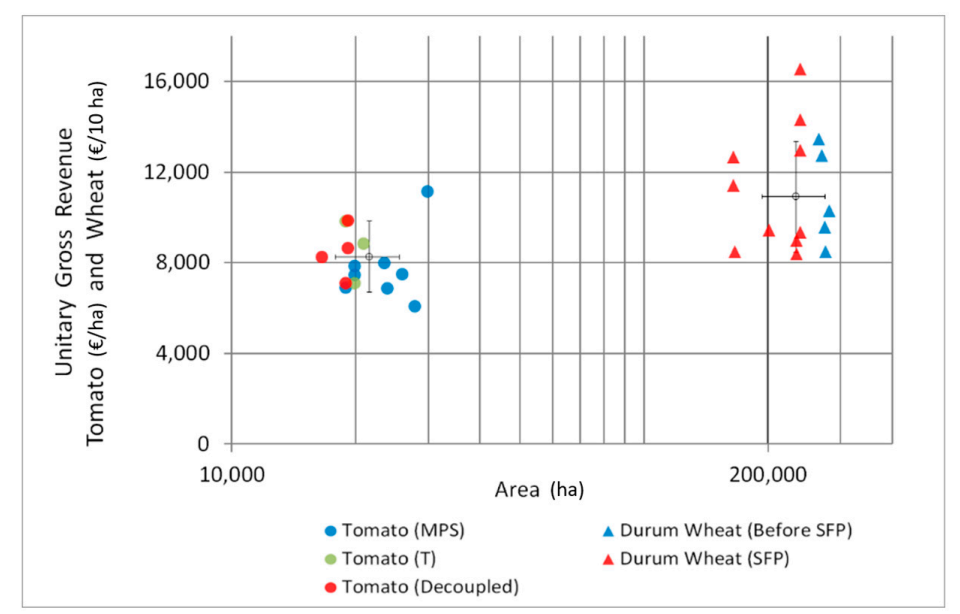

Figure 4. Unitary gross revenue and crop area: comparison between tomato and durum wheat under different support schemes over the time. In detail, for processing tomato: 2000-2007, the period with the market price support scheme (MPS); 2008-2010, the period with the transition scheme (T); and 2011-2014, the decoupled period (Decoupled). For durum wheat: 2000-2004, the period with the coupled support scheme (Before SFP); and 2005-2014, the period with single farm payment (SFP). 
The support scheme for durum wheat was always strongly coupled and focused on traditional production areas [46]. During the analysed period, the support scheme was deeply changed to overcome overproduction and stabilize farmers' income. For the period 2000-2004 (named Before Single Farm Payment in Figure 4), durum wheat was supported mainly through a market price support, together with a direct support per hectare and a premium for traditional areas [47]. Between 2005 and 2009 (named SFP in Figure 4), the effect of the Fischler Reform was to change the support scheme from "coupled" to "decoupled" and to implement eligible areas. In detail, a single farm payment (SFP) was introduced based on farmers' payments claimed in the period 2000-2002 and on eligible hectares of land [11]. During the period 2010-2014 (named SFP in Figure 4), with the health check reform on the SFP, the full decoupling process of the CAP scheme was achieved [48].

The dataset reporting the support supplied for durum wheat over the studied period was extracted from the database collected by the Network for Agricultural Economic Reporting (RICA). In detail, on the basis of a sample of farms in the area of interest, the intensity of a support per hectare was derived. On the basis of the collected data, the unitary gross revenue of farming activity is adopted as the sum of annual GPV and subsidies, divided by specific crop area to obtain unitary values. A comparison between unitary gross revenue and crop area is shown in Figure 4 for the analysed period.

From Figure 4, it seems that both the crop extensions decreased, while the unitary gross revenue appears more stable under decoupled support scheme only for processing tomato. The persistent variability of wheat unitary gross revenue, regardless of support scheme, could probably be due to climate-dependence of crop yield and to the influence of international market variability. The proposed methodology and the developed models' aims at an interpretation of the influence of each selected driver on crop area changes.

\section{Results}

\subsection{Development of Interpretative Models}

For the processing tomato, the observed change of crop land during the period of interest has shown a reduction of around $35.8 \%$. The relationships between processing tomato area and its drivers are shown in Figure $5 \mathrm{a}, \mathrm{b}$. The distinction is in the relationship between tomato area and subsidies, since, under MPS and T support schemes, the change in tomato area is related to subsidies which, in turn, is related to the crop yield of the previous year, as shown in Figure 5a. While, when subsidies are decoupled from production, the tomato area is related to a fixed subsidy without connection to crop yield (Figure $5 b$ ).

According to the conceptual maps in Figure 5a,b, the multi-regression model of processing tomato area (MRM-T) is expressed through Equation (1):

$$
A_{T}(t)=\overline{\mathrm{A}}_{T}\left[\left(c_{S} S(t)^{E_{S}}\right)+\left(c_{M} M(t-1)^{E_{M}}\right)+\left(c_{Y} Y(t-1)^{E_{Y}}\right)-\left(c_{S I} S I(t)^{E_{S I}}\right)\right]
$$

where: $A_{T}(t)$ is the tomato area (ha) at year $t ; \overline{\mathrm{A}}_{T}$ is the historical average value of $A_{T}, S(t), M(t-1)$, $Y(t-1), S I(t)$ are, respectively, the subsidy $(€ / \mathrm{ha})$ at year $t$, the market price $(€ / 100 \mathrm{~kg})$ at year $t-1$, the crop yield (100 kg/ha) at year $t-1$, and the surface water stress index at year $t ; c_{i}$ and $E^{i}$ are, respectively, the coefficients and exponents of each driver representing importance of each driver on the others.

Similarly, the crop area for durum wheat was characterized by strong fluctuations with reductions up to $41 \%$ between 2002 and 2011. The multi-regression analysis was based on the variability of market price, CAP subsidies, and crop yield, according to the interaction loops deriving from the conceptual maps in Figure $5 \mathrm{c}, \mathrm{d}$. In detail, both conceptual maps support the hypothesis that the crop area in one year depends on the market price and crop yield of the previous year. The difference in the two maps is in the relationship between durum wheat area and subsidies which, in the case of subsidies coupled with production (i.e., before SFP in Figure 4), asserts that the durum wheat area is related to the subsidies paid for the production of the previous year (Figure 5c). Under the decoupled scheme 
(i.e., SFP in Figure 4) the durum wheat area is related only to the subsidies attached to fixed eligible areas (assumed invariant from 2005 on) (Figure 5d).

According to the two conceptual maps for durum wheat, the multi-regression model (MRM-W) is expressed through Equation (2):

$$
A_{W}(t)=\overline{\mathrm{A}}_{W}\left[\left(c_{S} S(t)^{E_{S}}\right)+\left(c_{M} M(t-1)^{E_{M}}\right)+\left(c_{Y} Y(t-1)^{E_{Y}}\right)\right]
$$

where $A_{W}$ is the durum wheat area (ha) at year $t ; \overline{\mathrm{A}}_{W}$ is the historical average value of $A_{W}, S(t)$, $M(t-1), Y(t-1)$ are, respectively, subsidies $(€ / \mathrm{ha})$ at year $t$, the market price $(€ / 100 \mathrm{~kg})$ at year $t-1$, and the crop yield (100 kg/ha) at year $t-1$; and $c_{i}$ and $E^{i}$ are the coefficients and exponents of each driver, respectively.

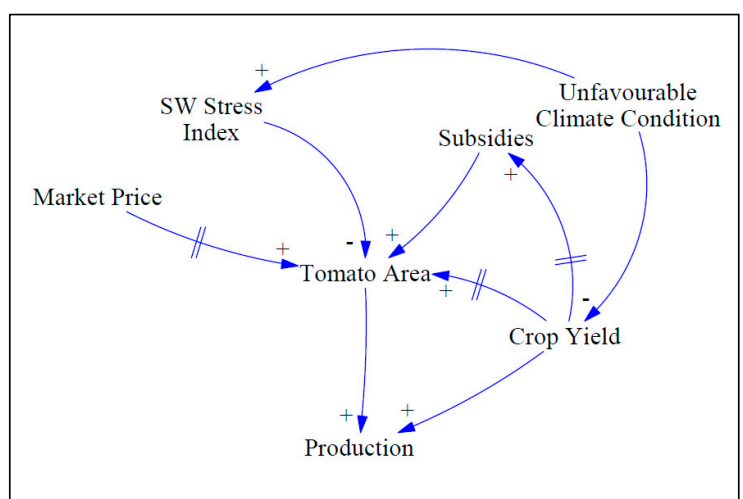

(a)

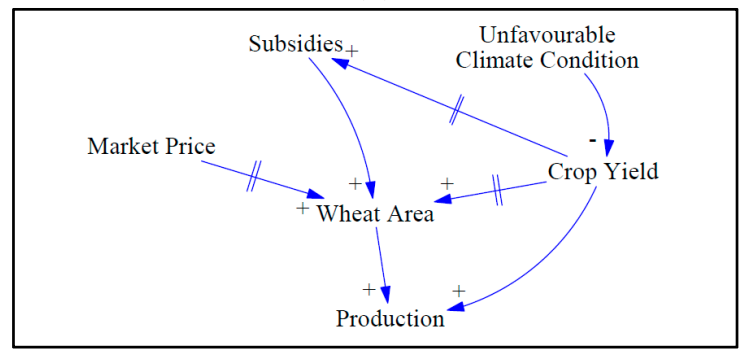

(c)

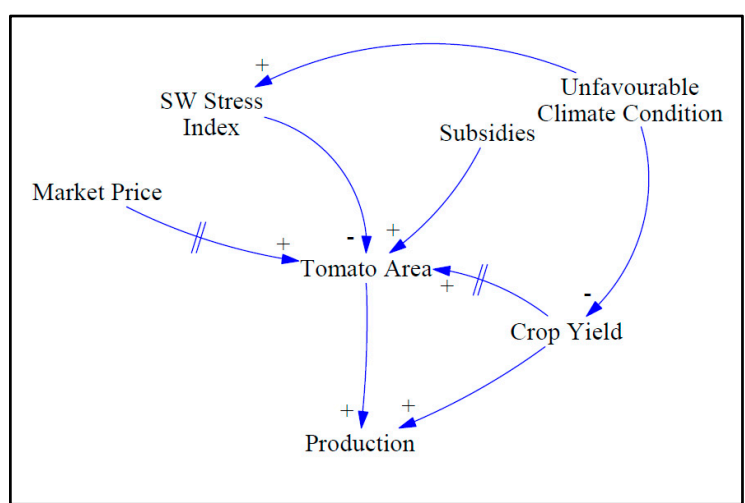

(b)

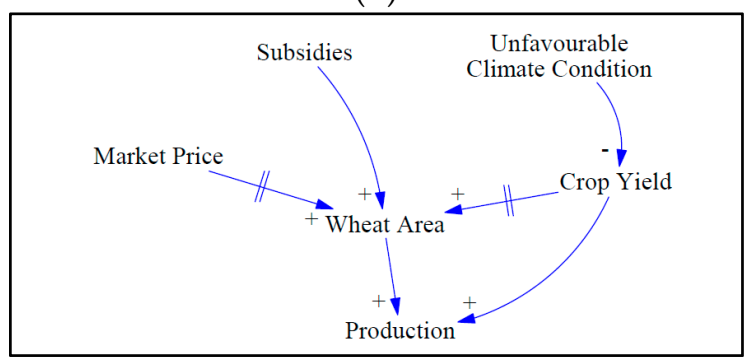

(d)

Figure 5. Conceptual maps: relations (arrows) between variables with polarity (symbols) and delay (ticked arrows). (a) Tomato area under the coupled support scheme; (b) tomato area under the decoupled support scheme; (c) wheat area under the coupled support scheme; and (d) wheat area under the decoupled support scheme.

\subsection{Parameterization of Models Components}

\subsubsection{Multi-Regression Models (MRM)-Tomato Parameterization}

Equation (1) contains four pairs of parameters, one for each driver. The study period was divided into two parts in order to distinguish the effects of CAP support regimes, namely coupled and decoupled support. Therefore, two specific sets of parameters were estimated. The first period from 2000 to 2010, corresponding to the market price support phase (MPS) and the transition phase (T), is characterized by remarkable variability of all considered drivers, including stress water conditions $(S I>0)$. Before running the calibration with the PEST ${ }^{\circledR}$ tool, the MRM-T function was bounded at the upper and lower limits, respectively 30,000 and 19,000 ha from the observation record. Using the abovementioned datasets, the parameters were estimated and their values are shown in Table 1.

Among the calibration results for MRM-T, the null value for $c_{Y}$ is due to the fact that the crop yield is already considered throughout the coupled payment period (see Section 4.1). Conversely, during 
the second period, from 2011 to 2014, CAP subsidies became decoupled from production volumes, but were paid to long-established producers at a constant level of support related to a fixed crop area. Thus, there was no influence of subsidies on the variation of cropping area; in fact, the calibrated value of $c_{S}$ is null. Moreover, in this period, no water stress condition occurred, while the other drivers sensibly changed. After a slight refinement of the lower bound area to 16,760 (historic value) the MRM-T function was calibrated and the corresponding parameter values are reported in Table 1.

Table 1. Estimated values and confidence limits of parameters.

\begin{tabular}{|c|c|c|c|c|c|c|c|}
\hline \multirow{4}{*}{ Parameters } & \multicolumn{4}{|c|}{ MRM-T } & \multirow{2}{*}{\multicolumn{3}{|c|}{$\begin{array}{c}\text { MRM-W } \\
2000-2014\end{array}$}} \\
\hline & & \multicolumn{2}{|l|}{ 2000-2010 } & \multirow{3}{*}{$\begin{array}{c}\text { 2011-2014 } \\
\text { Estimated } \\
\text { Value }\end{array}$} & & & \\
\hline & \multirow{2}{*}{$\begin{array}{l}\text { Estimated } \\
\text { Value }\end{array}$} & 95\% Confic & nce Limits & & \multirow{2}{*}{$\begin{array}{l}\text { Estimated } \\
\text { Value }\end{array}$} & \multicolumn{2}{|c|}{ 95\% Confidence Limits } \\
\hline & & Lower Limit & Upper Limit & & & Lower Limit & Upper Limit \\
\hline$c_{S}$ & $3.80 \times 10^{-4}$ & $7.56 \times 10^{-5}$ & $6.85 \times 10^{-4}$ & 0 & $1.58 \times 10^{-3}$ & $-1.67 \times 10^{-3}$ & $4.84 \times 10^{-3}$ \\
\hline$c_{M}$ & $1.15 \times 10^{-1}$ & $3.43 \times 10^{-1}$ & $5.72 \times 10^{-1}$ & $9.35 \times 10^{-3}$ & $1.91 \times 10^{-3}$ & $-1.79 \times 10^{-2}$ & $2.17 \times 10^{-2}$ \\
\hline$c_{Y}$ & 0 & 0 & 0 & $9.50 \times 10^{-4}$ & $1.02 \times 10^{-3}$ & $-2.04 \times 10^{-2}$ & $2.24 \times 10^{-2}$ \\
\hline$c_{S I}$ & $4.79 \times 10^{-1}$ & $2.28 \times 10^{-1}$ & $7.32 \times 10^{-1}$ & $4.79 \times 10^{-1}$ & - & - & - \\
\hline$E_{S}$ & $9.68 \times 10^{-1}$ & $7.73 \times 10^{-1}$ & 1.162 & 1 & 1.057 & $-2.50 \times 10^{-2}$ & 2.311 \\
\hline$E_{M}$ & $7.15 \times 10^{-1}$ & $-9.86 \times 10^{-1}$ & 2.416 & $8.84 \times 10^{-1}$ & $9.97 \times 10^{-1}$ & $-9.85 \times 10^{-1}$ & 2.981 \\
\hline$E_{Y}$ & 1 & 1 & 1 & 1.004 & $9.99 \times 10^{-1}$ & -1.253 & 3.251 \\
\hline$E_{S I}$ & 3.805 & -6.233 & 13.843 & 3.805 & - & - & - \\
\hline
\end{tabular}

\subsubsection{Multi-Regression Models (MRM)-Wheat Parameterization}

Differently for the MRM-T, Equation (2) contains only three pairs of parameters (durum wheat being assumed as a rain-fed crop), one for each driver. The study period for durum wheat production was characterised by fluctuations in the drivers' values, particularly as a consequence of the Fischler Reform which started the decoupling process in 2005 with strong impacts on durum wheat production. Therefore, before 2005, the wheat area was related mostly to the subsidies of the previous year (i.e., support coupled with crop production of the previous year), while from 2005 to 2014 subsidies of the same year were considered (the effect of decoupling of the support). Based on such information on the PAC support scheme, the observed annual crop areas, and constraining the model variability between the historical values (285,000 and 165,000 ha), the MRM-W represented in Equation (2) was calibrated and the parameters' values are shown in Table 1 . The calibration of model parameters was performed independently from the support scheme, thus, over the whole study period, due to poor calibration results were obtained with respect to two periods with different support schemes.

The confidence limits, which provide only an indication of parameter uncertainty, were obtained from the PEST ${ }^{\circledR}$ tool. They rely on a linear assumption which may not extend as far in the parameter space as the confidence limits themselves. Concerning the MRM-T for the period 2011-2014, the estimated parameters do not present the corresponding uncertainty due to the short number of the observations (four values).

In both calibrations, the estimated confidence limits showed an acceptable range compared to the parametrization limits fixed before the optimization process. Only for $E_{S I}$ was a wider range of confidence limits found, probably due to a limited number of years with SW scarcity $(S I>0)$.

\subsection{Validation}

A comparison between model estimates of crop areas from the MRM-T and MRM-W and the historic values was performed as validation for the period 2000-2014 and is shown in Figure 6. 


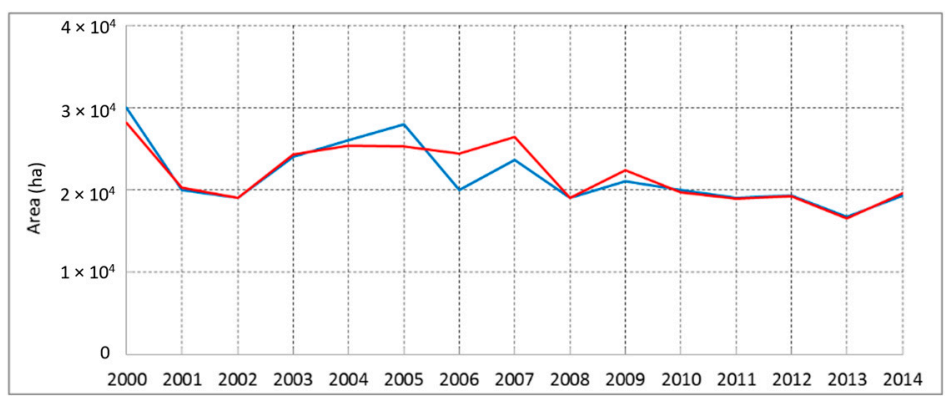

(a)

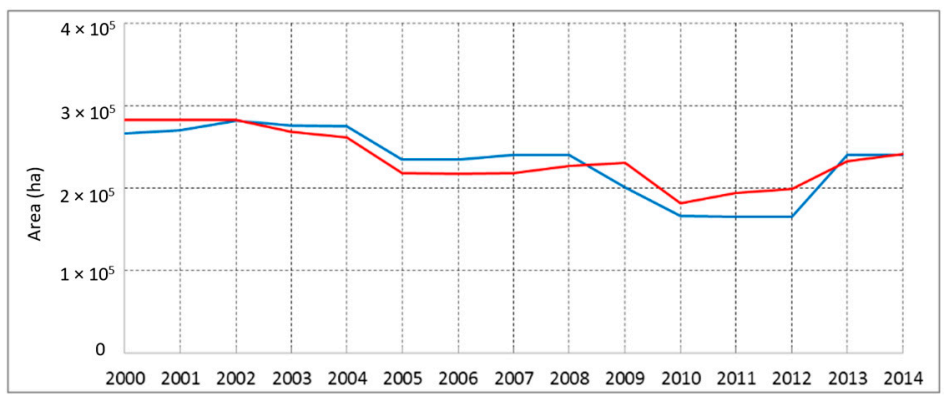

(c)

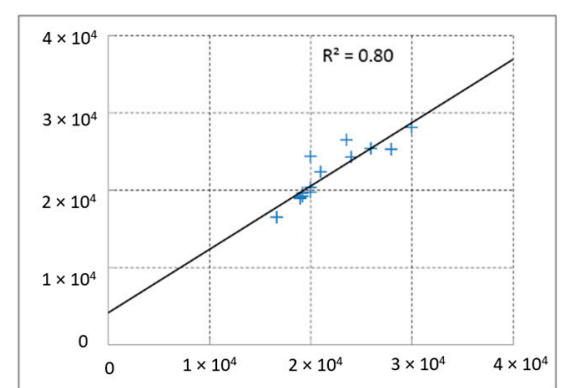

(b)

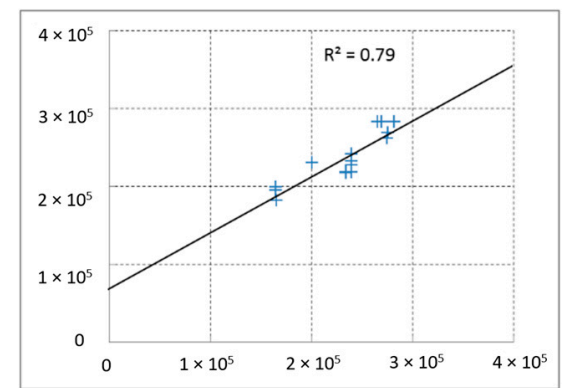

(d)

Figure 6. Simulated (red line) and observed (blue line) values of annual crop area for processing tomato (a) and durum wheat (c). Scatterplots are reported on the corresponding right panels, $(\mathbf{b}, \mathbf{d})$, with the $x$-axis and $y$-axis denoting, respectively, the simulated and observed values.

The crop area changes simulated for tomato have shown a good agreement with respect to the historic values (Figure 6a,b), with a determination coefficient of 0.80 . Only in 2006 was a marked difference between observed and simulated area found, probably due to the over-production reported for 2004, which caused a severe reduction of the market price in 2005 (CIA Annual Report 2005) and consequent discouragement of farmers, also remarked by Arfini [44].

A good agreement was also found between simulated changes of the durum wheat area and the corresponding historic values (Figure $6 \mathrm{c}, \mathrm{d}$ ), with a determination coefficient of 0.79 . The simulated changes in durum wheat area showed less variable values than the observed ones, probably due to the available subsidies dataset, which refers to the general category of cereal crops.

Though the correlation is quite good for both crop area models, simulated durum wheat areas are overestimated by about $28 \%$, while the overestimation for tomato areas is around $18 \%$.

\subsection{Sensitivity Analysis to Evaluate the Relative Influence of Area Variability Drivers}

Using the abovementioned SA approach for the crop area variability for processing tomato, different conditions of irrigation water availability occurred during the period with the coupled support scheme (from 2000 to 2010). Therefore, the results of SA were classified into three classes of water availability, identified as regular $(S I=0)$, intermediate $(0<S I<1)$, and drought condition $(S I=1)$.

Accordingly, the relative influence of each driver of the area variability was evaluated as its average weight under different conditions of water availability (Table 2). For the period with the decoupled support scheme 2011-2014, only regular conditions of irrigation availability were recorded. Therefore, synthetic data records were used to estimate the influence of input drivers under intermediate and drought conditions, assuming the average values of market and yield drivers from the regular condition (Table 2). The results of the SA in Table 2 reveal the major drivers of crop area variability under different support schemes and climatic conditions. 
Table 2. Sensitivity analysis for the multi-regression model of processing tomato area (MRM-T).

\begin{tabular}{ccccccc}
\hline \multirow{2}{*}{ Drivers } & \multicolumn{3}{c}{ Coupled } & \multicolumn{3}{c}{ Decoupled } \\
\cline { 2 - 6 } & Regular & Intermediate & Drought & Regular & Intermediate & Drought \\
\hline$S$ & $54 \%$ & $57 \%$ & $41 \%$ & $0 \%{ }^{2}$ & $0 \%{ }^{2}$ & $0 \%{ }^{2}$ \\
$M$ & $46 \%$ & $40 \%$ & $33 \%$ & $8 \%$ & $7 \%$ & $4 \%$ \\
$S I$ & $0 \%$ & $3 \%$ & $26 \%$ & $0 \%$ & $3 \%$ & $36 \%$ \\
$\boldsymbol{Y}$ & $0 \%{ }^{1}$ & $0 \%{ }^{1}$ & $0 \%{ }^{1}$ & $92 \%$ & $90 \%$ & $60 \%$ \\
\hline
\end{tabular}

Notes: ${ }^{1}$ During coupled period, the effect of crop yield is included in the value of subsidies. ${ }^{2}$ During decoupled period, the support had no effects on the cropping area variation, see Section 4.2.1.

As far as the variability of durum wheat crop areas is concerned, different support schemes were implemented during the study period with changing levels of support. Particularly, a marked reduction (about 50\%) was observed. Moreover, strong fluctuations of crop yield were reported, which could be related to the positive or negative climate conditions [40]. Therefore, to estimate the relative influence of each driver under different levels of crop yield, the SA was organized according to the percentiles of the historic crop yield (i.e., the $33 \%$ and $66 \%$ percentiles). In detail, the regular yield condition was defined for $Y>3.21 \mathrm{t} / \mathrm{ha}$, intermediate for $2.91<Y<3.21 \mathrm{t} / \mathrm{ha}$, and drought for $Y<2.91 \mathrm{t} / \mathrm{h}$. Thus, the results of the SA highlighted the relative influence of each driver of the area variability in terms of its average weight under different rainfall conditions (Table 3).

Table 3. Sensitivity analysis for multi-regression model (MRM-W).

\begin{tabular}{ccccc}
\hline Drivers & Regular & Intermediate & Drought & Average \\
\hline$S$ & $91 \%$ & $94 \%$ & $92 \%$ & $92.3 \%$ \\
$M$ & $5 \%$ & $3 \%$ & $5 \%$ & $4.3 \%$ \\
$\boldsymbol{Y}$ & $4 \%$ & $3 \%$ & $3 \%$ & $3.3 \%$ \\
\hline
\end{tabular}

\section{Discussion}

Different changes in the total agricultural area have been observed in the study area, which regarded both rain-fed and irrigated crops. For the latter ones, the observed changes are mainly due to the reduction of tomato area and of vineyard as a function of different influencing drivers. For instance, the processing tomato production has shown a fluctuating trend reflecting European and Italian agricultural policy, as well as climate and economic factors [49], whereas the reduction of vineyard area was mainly due to the CAP extirpation payments (CE No. 479/2008).

As a whole, the accuracy of model results can be considered good. The variability of cropping area devoted to processing tomato was interpreted by means of the MRM-T, which considers four forcing drivers, which are market price, crop yield, SI, and subsidies. Specific calibrations were performed for coupled and decoupled support schemes. Considering the heterogeneity of the considered drivers, the value of each parameter is representative of both the drivers' influence and the necessary normalization of the model equation. According to the results, under the coupled support, the crop yield had no influence on the area variability. When water availability for irrigation was regular (i.e., no restrictions in water block tariff), the most influencing driver was the intensity of subsidies $(54 \%)$, followed by the market price factor $(46 \%)$ while, with intermediate water availability (i.e., moderate water restrictions), subsidies were the most influencing driver (57\%), followed by market prices $(40 \%)$, and then the SI (3\%). Under severe drought conditions, the relative importance of drivers was markedly changed, with subsidies weighing as much as $41 \%$, followed by market price at $33 \%$, and the SI at $26 \%$. On the basis of such results for tomato crops, subsidies were the most influencing driver under the coupled support scheme (average value about $51 \%$ ), followed by market price variability (average value $40 \%$ ), while the influence of the SI, as expected, is evident only in cases 
of drought. In light of these results, the observed reduction of processing tomato area was mainly related to the change in CAP support scheme.

Under the decoupled support scheme, despite the irrigation seasons being regular in the observation period, the SA was performed for the three levels of water availability (Table 2). The effect of the subsidy amount on the area variability disappeared $\left(c_{S}=0\right)$ as subsidies became constant (decoupled from production amount) and were actually paid only to historical areas (i.e., support was not extended outside those zones). Concerning the remaining drivers of crop area variability, under regular water availability, the most influencing turned out to be the crop yield (92\%), followed by market price $(8 \%)$. Under moderate water restriction, once more, the crop yield was the most influencing driver $(90 \%)$, followed by market price $(7 \%)$, and then SI $(3 \%)$. Then, for severe drought seasons, crop yield was the most influencing driver (59\%), followed by SI (36\%) and market price (4\%). In conclusion, under the decoupled support scheme, the most influential driver has become crop yield (average value about $80 \%$ ), while water accessibility becomes important only during drought periods. These results highlighted the effect of water stress on the reduction of crop area. Moreover, simulated reduction of cropping area between periods with coupled and decoupled payment is in line with the findings of other studies $[49,50]$.

In the case of tomato, direct and decoupled payment schemes presumably have incentivised farmers to orient farming decisions to markets. This enhances competitiveness, but in the context of increasing climate variability, it also exposes farmers to yield fluctuation. Although a number of risk management instruments are available to complement farmers' coping with large income losses, no evidence regarding the CAP 2014-2020 effects is available yet [51]. Policy-makers should pay great attention to yield fluctuation, including more specific risk management tools within the CAP.

Additionally, during drought periods the reduction of surface water accessibility is likely to produce further negative impacts on groundwater resources. More specifically, while droughts may limit farms supplied only by surface water, farms supplied both by surface and groundwater may take advantage.

The variability of the durum wheat crop area was interpreted by means of the MRM-W model, which considers three forcing drivers, i.e., market price, crop yield and subsidy intensity. In this case, an overall calibration was performed with respect to the study period and the model structure resulted in being almost linear since only the subsidy's exponent was different from unity (Table 1). The SA was performed with regard to three levels of crop yield (Table 3), supposedly directly linked to the climatic conditions. As a whole, subsidies showed to be always the most influencing driver (with an average value of about $92 \%$ ). These findings are in line with those found in [52]. In fact, there was a decrease of cropping area simultaneously to the change of the support scheme from "coupled" to "decoupled" and to the implementation of eligible areas. From the environmental standpoint, the observed reduction could increase the exploitation of water resources, due to the increasing interest of farmers towards irrigated crops, being more profitable than durum wheat production.

Generally, it was assumed that after decoupling, the CAP's influence on farmers' decision-making processes would be very limited. Results in this research have confirmed these assumptions only in the case of irrigated crops, such as processing tomato, in line with Giannoccaro and Berbel's [11] results of the CAP's slight influence on water use after the decoupling scheme.

\section{Conclusions}

Bio-physical and socio-economic drivers were deeply analysed with regard to a wealthy agricultural area where both water-intensive tomato crops and rain-fed cereal crops underwent a substantial areal change.

According to the conceptual maps two distinct multi-regression models were developed to investigate the inter-annual variability of crop land devoted to tomato (an intensive crop with a high water requirement) and durum wheat (an extensive and rain-fed crop). The adopted models allowed the ex-post interpretation of the observed variability of crop area over the study period, 
also highlighting the different weights of each driver under the changing subsidies' schemes and accessibility to irrigation water. Concerning the CAP reforms, the decoupled scheme explained the reduction of crop area for both tomato and durum wheat crops. In fact, the role of agricultural subsidies was highlighted for both crops as the main drivers for farming. In detail, the durum wheat area remains strongly influenced by subsidies, as the extension of the cropped area tends to the eligible area. Therefore, a reduction of support could further reduce the rain-fed crop area and increase the interest of farmers toward more profitable irrigated crops. Conversely, under the decoupled support scheme, the tomato crop appeared highly influenced by crop yield, causing an increase of risk exposure for farmers, especially under drought conditions or, more generally, when water supply restrictions are introduced. Consequently, to prevent further depletion of groundwater resources and stabilize farmers' incomes, under the increase of yield-related risks, more specific risk management tools may be included in future CAP reforms.

In conclusion, the multi-regression modelling approach can help understand the effects of agricultural and water policies on the crop pattern change, thus, on water resources exploitation, by separating the effects of other variability sources. Provided that sufficient observations are available, the adopted approach enabled to effectively weigh the roles of human and physical drivers influencing large-scale cropping patterns and related irrigation needs. The model validation is, nevertheless, subject to certain limitations, such as the availability of crop- and site-specific multi-annual datasets, and the influence of crop production stocks from previous years on farmers' decisions.

Acknowledgments: This research is co-funded by the FCRP foundation under the grant No. 3329/2015 for the MIGRAD Project.

Author Contributions: Ivan Portoghese and Giacomo Giannoccaro conceived and designed the experimental approach; Donato Zingaro collected and analyzed the data; Donato Zingaro, Ivan Portoghese and Giacomo Giannoccaro developed interpretative models and wrote the paper.

Conflicts of Interest: The authors declare no conflict of interest.

\section{References}

1. Godfray, H.C.J.; Beddington, J.R.; Crute, I.R.; Haddad, L.; Lawrence, D.; Muir, J.F.; Pretty, J.; Robinson, S.; Thomas, S.M.; Toulmin, C. Food security: The challenge of feeding 9 billion people. Science 2012, 327, 812-818. [CrossRef] [PubMed]

2. Foley, J.A. Global Consequences of Land Use. Science 2005, 309, 570-574. [CrossRef] [PubMed]

3. Food and Agriculture Organization. The State of the World's Land and Water Resources for Food and Agriculture; FAO and Earthscan: New York, NY, USA, 2011; pp. 3-5.

4. Siebert, S.; Burke, J.; Faures, J.M.; Frenken, K.; Hoogeveen, J.; Döll, P.; Portmann, F.T. Groundwater use for irrigation-A global inventory. Hydrol. Earth Syst. Sci. 2010, 14, 1863-1880. [CrossRef]

5. Foley, J.A.; Ramankutty, N.; Brauman, K.A.; Cassidy, E.S.; Gerber, J.S.; Johnston, M.; Mueller, N.D.; O'Connell, C.; Ray, D.K.; West, P.C.; et al. Solutions for a cultivated planet. Nature 2011, 478, 337-342. [CrossRef] [PubMed]

6. Dalin, C.; Wada, Y.; Kastner, T.; Puma, M.J. Groundwater depletion embedded in international food trade. Nature 2017, 543, 700-704. [CrossRef] [PubMed]

7. Green, T.R.; Taniguchi, M.; Kooi, H.; Gurdak, J.J.; Allen, D.M.; Hiscock, K.M.; Treidel, H.; Aureli, A. Beneath the surface of global change: Impacts of climate change on groundwater. J. Hydrol. 2011, 405, 532-560. [CrossRef]

8. Wiggering, H.; Steinhardt, U. A conceptual model for site-specific agricultural land-use. Ecol. Model. 2015, 295, 42-46. [CrossRef]

9. Borrell, B.; Hubbard, L. Global Economic Effects of the EU Common Agricultural Policy. Econ. Aff. 2000, 20, 18-26. [CrossRef]

10. Barnes, A.; Sutherland, L.; Toma, L.; Matthews, K.; Thomson, S. The effect of the Common Agricultural Policy reforms on intentions towards food production: Evidence from livestock farmers. Land Use Policy 2016, 50, 548-558. [CrossRef] 
11. Giannoccaro, G.; Berbel, J. Influence of the Common Agricultural Policy on the farmer's intended decision on water use. Span. J. Agric. Res. 2011, 9, 1021-1034. [CrossRef]

12. Portoghese, I.; D'Agostino, D.; Giordano, R.; Scardigno, A.; Apollonio, C.; Vurro, M. An integrated modelling tool to evaluate the acceptability of irrigation constraint measures for groundwater protection. Environ. Model. Softw. 2013, 46, 90-103. [CrossRef]

13. Giordano, R.; D’Agostino, D.; Apollonio, C.; Scardigno, A.; Pagano, A.; Portoghese, I.; Lamaddalena, N.; Piccinni, A.F.; Vurro, M. Evaluating acceptability of groundwater protection measures under different agricultural policies. Agric. Water Manag. 2015, 147, 54-66. [CrossRef]

14. Perry, C.; Steduto, P. Does Improved Irrigation Technology Save Water? FAO: Cairo, Egypt, 2017; pp. 36-39.

15. Wijinands, F.W.T. Crop rotation in organic farming: Theory and practice. In Designing and Testing Crop Rotations for Organic Farming, Proceedings from an International Workshop; Danish Research Centre for Organic Farming: Tjele, Denmark, 1999; pp. 21-35.

16. Stone, N.D.; Buick, R.D.; Roach, J.W.; Scheckler, R.K.; Rupani, R. The planning problem in agriculture: Farm-level crop rotation planning as an example. AI Appl. 1992, 6, 59-75.

17. Rounsevell, M.D.A.; Annetts, J.E.; Audsley, E.; Mayr, T.; Reginster, I. Modelling the spatial distribution of agricultural land use at theregional scale. Agric. Ecosyst. Environ. 2003, 95, 465-479. [CrossRef]

18. Dury, J.; Schaller, N.; Garcia, F.; Reynaud, A.; Bergez, J.E. Models to support cropping plan and crop rotation decisions. Agron. Sustain. Dev. 2012, 32, 567-580. [CrossRef]

19. Winder, N.; Jeffrey, P.; Lemon, M. Simulation of crop choice dynamics: An application of nested Master-Equation models. Étud. Rech. Syst. Agraires Dév. 1998, 31, 175-189. Available online: http://prodinra.inra.fr/ft?id= 3E5499F0-FF3D-40A2--800F-9BA042BF8226 (accessed on 20 June 2017).

20. Holt, M.T. A linear approximate acreage allocation model. J. Agric. Resour. Econ. 1999, 24, $383-397$. Available online: http:/ / www.jstor.org/stable/40987029 (accessed on 20 June 2017).

21. Masciopinto, C. Pumping-well data for conditioning the realization of the fracture aperture field in groundwater flow models. J. Hydrol. 2005, 309, 210-228. [CrossRef]

22. Portoghese, I.; Vurro, M.; Lopez, A. Managing Water Resources under Climate Uncertainty; Springer International Publishing: Cham, Switzerland, 2015; pp. 177-195.

23. Kottek, M.; Grieser, J.; Beck, C.; Rudolf, B.; Rubel, F. World Map of the Köppen-Geiger climate classification updated. Meteorol. Z. 2006, 15, 259-263. [CrossRef]

24. Istat Census 2010. Available online: http://www.istat.it/it/censimento-permanente/censimenti-precedenti/ agricoltura/agricoltura-2010 (accessed on 10 December 2016).

25. Lamaddalena, N. Water Management for Drought Mitigation in the Mediterranean; CIHEAM: Bari, Italy, 2004; pp. 245-265.

26. Giannoccaro, G.; Prosperi, M.; Zanni, G. Economic effects of legislative framework changes in groundwater use rights for irrigation. Water 2011, 3, 906-922. [CrossRef]

27. Polemio, M.; Casarano, D.; Limoni, P.P. Apulian coastal aquifers and management criteria. In Proceedings of the SWIM 21-21st Salt Water Intrusion Meeting, Azores, Portugal, 21-26 June 2010; Available online: http:/ / www.earth-prints.org/handle/2122/6151 (accessed on 12 May 2017).

28. Guyennon, N.; Romano, E.; Portoghese, I. Long-term climate sensitivity of an integrated water supply system: The role of irrigation. Sci. Total Environ. 2016, 565, 68-81. [CrossRef] [PubMed]

29. Istat Database. Available online: http:/ / dati.istat.it/ (accessed on 20 May 2016).

30. Ismea Database. Available online: http://www.ismeamercati.it (accessed on 19 December 2016).

31. Zingaro, D.; Portoghese, I.; Pagano, A.; Giordano, R.; Vurro, M. Assessing groundwater use in irrigation districts with multiple resources (MIGRAD). In Proceedings of the 10th World Congress of EWRA on Water Resources and Environment "Panta Rhei", Athens, Greece, 5-9 July 2017; pp. 1957-1963.

32. Giordano, R.; Brugnach, M.; Pluchinotta, I. Ambiguity in Problem Framing as a Barrier to Collective Actions: Some Hints from Groundwater Protection Policy in the Apulia Region. Group Decis. Negot. 2016, 1-22. [CrossRef]

33. Verburg, P.H.; de Koning, G.H.J.; Kok, K.; Veldkamp, A.; Bouma, J. A spatial explicit allocation procedure for modelling the pattern of land use change based upon actual land use. Ecol. Model. 1999, 116, 45-61. [CrossRef]

34. Pagano, A.; Pluchinotta, I.; Giordano, R.; Vurro, M. Drinking water supply in resilient cities: Notes from L'Aquila earthquake case study. Sustain. Cities Soc. 2017, 28, 435-449. [CrossRef] 
35. Doherty, J. Water Down under 94: Preprints of Papers, Adelaide, South Australia; Institution of Engineers: Barton, Australia, 1994; pp. 551-554.

36. Pianosi, F.; Beven, K.; Freer, J.; Hall, J.W.; Rougier, J.; Stephenson, D.B.; Wagener, T. Sensitivity analysis of environmental models: A systematic review with practical workflow. Environ. Model. Softw. 2016, 79, 214-232. [CrossRef]

37. Saltelli, A.; Ratto, M.; Andres, T. Global Sensitivity Analysis: The Primer; John Wiley \& Sons Ltd.: Chichester, UK, 2008; pp. 1-9.

38. Campbell, D.J.; Lusch, D.P.; Smucker, T.A.; Wangui, E.E. Multiple methods in the study of driving forces of land use and land cover change: A case study of SE Kajiado District, Kenya. Hum. Ecol. 2005, 33, 763-794. [CrossRef]

39. Barbier, E.B. The economic determinants of land degradation in developing countries. Philos. Trans. R. Soc. B Biol. Sci. 1997, 352, 891-899. [CrossRef]

40. Ventrella, D.; Giglio, L.; Charfeddine, M.; Lopez, R.; Castellini, M.; Sollitto, D.; Castrignanò, A.; Fornaro, F. Climate change impact on crop rotations of winter durum wheat and tomato in southern Italy: Yield analysis and soil fertility. Ital. J. Agron. 2012, 7, 100-108. [CrossRef]

41. Terra e Vita. Available online: http://www.terraevita.it/il-pomodoro-da-industria-conviene-ancora/ (accessed on 15 September 2016).

42. Cantore, N.; Kennan, J.; Page, S. CAP Reform and Development Introduction, Reform Options and Suggestions for Further Research; Overseas Development Institute: London, UK, 2011.

43. Allen, B.; Hart, K. Meeting the EU's environmental challenges through the CAP-How do the reforms measure up? Asp. Appl. Biol. 2013, 118, 9-22.

44. Arfini, F.; Donati, M.; Petriccione, G.; Solazzo, R. An Impact Assessment of the Future CAP Reform on the Italian Tomato Sector. In Proceedings of the 109th Seminar EAAE "The CAP after the Fischler Reform: National Implementations, Impact Assessment and the Agenda for Future Reforms", Viterbo, Italy, 20-21 November 2008; pp. 1-24.

45. Terra e Vita. Available online: http://www.terraevita.it/pomodoro-industria-al-cospetto-della-pac/ (accessed on 10 October 2016).

46. Donati, M.; Zuppiroli, M. Valutazione dell'impatto della Nuova Politica Agricola Comune sulla produzione del grano duro nelle regioni italiane. PAGRI 2003, 3, 21-50.

47. Cacchiarelli, L. La Trasmissione dei Prezzi e L'esercizio del Potere di Mercato Nella Filiera CerealicolaMolitoria-Pastaria tra Riforma PAC ed Eventi Congiunturali. Ph.D. Thesis, Università Degli Studi Della Tuscia di Viterbo, Viterbo, Italy, 17 June 2014.

48. Ciliberti, S.; Frascarelli, A. A critical assessment of the implementation of CAP 2014-2020 direct payments in Italy. Bio-Based Appl. Econ. 2015, 4, 261-277. [CrossRef]

49. Solazzo, R.; Donati, M.; Arfini, F.; Petriccione, G. A PMP model for the impact assessment of the Common Agricultural Policy reform 2014-2020 on the Italian tomato sector. New Medit 2014, 13, 9-19.

50. Cortignani, R.; Severini, S. The impact of reforming the Common Agricultural Policy on the sustainability of the irrigated area of Central Italy. An empirical assessment by means of a Positive Mathematical Programming model. In Proceedings of the 120th EAAE Seminar: "External Cost of Farming Activities: Economic Evaluation, Risk Considerations, Environmental Repercussions and Regulatory Framework", Chania, Greece, 2-4 September 2010.

51. Castañeda-Vera, A.; Garrido, A. Evaluation of risk management tools for stabilising farm income under CAP 2014-2020. Econ. Agrar. Recur. Nat. 2017, 17, 03-23. [CrossRef]

52. Siad, S.; Gioia, A.; Hoogenboom, G.; Iacobellis, V.; Novelli, A.; Tarantino, E.; Zdruli, P. Durum Wheat Cover Analysis in the Scope of Policy and Market Price Changes: A Case Study in Southern Italy. Agriculture 2017, 7, 12. [CrossRef]

(C) 2017 by the authors. Licensee MDPI, Basel, Switzerland. This article is an open access article distributed under the terms and conditions of the Creative Commons Attribution (CC BY) license (http://creativecommons.org/licenses/by/4.0/). 